\title{
Morphological Characterization of Gecko's (Eublepharis macularius) Glial Cells in Culture
}

\author{
Caracterización Morfológica de las Células Gliales del Gecko (Eublepharis macularius) en Cultivo
}

Jakub Grzesiak*; Krzysztof Marycz; Dariusz Szarek ${ }^{* * *}$ \& Wlodzimierz Jarmundowicz*

GRZESIAK, J.; MARYCZ, K.; SZAREK, D. \& JARMUNDOWICZ, W. Morphological characterization of Gecko's (Eublepharis macularius) glial cells in culture. Int. J. Morphol., 31(3):826-831, 2013.

SUMMARY: Central nervous system of reptiles has the ability to grow and regenerate during adult life of the animal. Therefore, cells creating CNS of this animal class should compound substances or molecules enabling neuroregeneration. Cells directly involved in this process have not been clearly characterized, especially in cell culture environment. Morphology of reptilian glial adherent cells should be known better to find any differences from mammalian CNS cells. We isolated glial cells from olfactory bulb and cerebrum from gecko (Eublepharis macularius) and cultured separately. We have observed populations of cells with proliferative capacity in both types of cultures. Also, we have detected lipid molecules deposits within their cytoplasm, which localization was correlated with mitochondria position. This information can be helpful in searching new bioactive substances involved in regeneration of central nervous system.

KEY WORDS: Glial cells; Neurogenesis; Neuroregeneration; Reptile.

\section{INTRODUCTION}

Central nervous system in reptiles, unlike in mammals, has the markedly greater ability to regenerate. Tail of a lizard can be severed and regrown with functional spinal cord within. This process is generated by proliferative structure called the blastema. It is a compound of stem cells, and is responsible for reconstruction of complete tail (Wang et al., 2009). Blastema is built up from undifferentiated mesenchymal stem cells (MSCs) or satellite cells, which have the proliferative and multilineage potential wider than adult stem cells of higher animals (Wang et al., 2011). During reptilian tail regeneration those particular cells migrate with bloodstream and from surrounding tissues into the wound site, where they proliferate and differentiate. This unique mechanism of spontaneous tail regeneration is typical for several species of reptiles, but the general CNS regenerative potential of this class is very significant. It suggests that reptilian CNS cells should somehow differ from mammalian CNS cells, which almost do not undertake the regeneration processes. They could have some unique organelles or synthesize some molecules, eg. proteins or lipids which are directly involved in CNS regeneration. Such factors have already been analyzed in mammalian cells by other researchers (Hannun \& Obeid, 2008; Ratajczak et al., 2012). Therefore, it seems to be important to understand the influence of different active molecules on reptilian cell cultures.

One of the biggest challenges for human medicine is the treatment of spinal cord injuries. In mammals, unlike in evolutionary lower animals, neuroneogenesis is highly limited so such acute health condition is almost irreversible. In adult mammalian brain, one of sparse structures which kept the neuroregeneration ability is olfactory bulb. Mammalian glial cells harbored in this brain region have neurogenic potential, but it is naturally restricted only to olfactory sense physiology. These cells were already used for experimental treatment for spinal cord injuries (RamonCueto \& Munoz-Quiles, 2011). It was shown also that these cells can be cultured in vitro and can be analyzed physiologically.

Lately we have started an experiment leading to finding differences between reptilian and mammalian glial cells. This cellular in vitro model would provide data if there

\footnotetext{
* Electron Microscopy Laboratory, University of Environmental and Life Sciences, Wroclaw, Poland.

** Department of Neurosurgery, Medical University Wroclaw, Poland.

This work was funded by NCN, grant number 1765/B/PO1/2011/40
} 
are any substances which enable regeneration of CNS in reptiles. Unfortunately we haven't found any information about such attempts, neither about morphology of cells in culture. Thus, we isolated cells from brains of lizards and put them on standard culture environment for morphological characterization of adherent populations. They were observed by means of light and fluorescent microscopy, with visualization of actin, nuclei, mitochondria and lipid deposits. Also changes in particular cell type numbers were detected. The main purpose of our research was to examine morphology of lizard's glial cells in particular culture environment. Information about their behavior could be the clue for detection of stem cell populations and for searching any differences from mammals. Knowledge about their detailed morphology is the first step in the way of bioactive substance detection.

\section{MATERIAL AND METHOD}

Animals. Tissues from 10 geckos (Eublepharis macularius) were kindly donated by Medical University of Wroclaw. Animals were used in other experiment, which Second Local Bioethic Commission approved (85/2010). Experiments with tissues do not require such approval. Their brains were surgically removed post mortem for culture. Tissues were transported in sterile Hanks' balanced salt (Sigma). Additionally, blood from ten individuals was collected for serum isolation. Serum samples were aliquoted and frozen for further usage.

Cell isolation and culture course. Prior to culture establishment, olfactory bulbs and cerebra were isolated for separated cultures. All tissue samples were extensively washed from blood traces in Hanks' balanced salt. Next, samples were minced with surgical scissors and incubated with $0,25 \%$ collagenase (Sigma) for 15 minutes in $37^{\circ} \mathrm{C} / 5 \% \mathrm{CO} 2$. After digestion, tissues were disrupted with syringe needle (20G) and centrifuged at $300 \mathrm{~g} / 2$ minutes. Supernatant was discarded, pellets were washed in Hanks' balanced salt and samples were centrifuged again. Next, cell pellets were dissolved in Dulbecco Modified Eagle Medium/F12: Ham's mixture (Sigma), supplemented by $5 \% \mathrm{FBS} / 5 \%$ reptile serum $/ 1 \%$ penicillin-streptomycin-amphotericin b. Cells were seeded into T-25 flasks and were maintained in $37^{\circ} \mathrm{C} /$ $5 \% \mathrm{CO} 2$, with medium change every 3 days.

Observations. Everyday observations were made by means of inverted phase-contrast microscope (AxioObserver.A1, Zeiss). Assessment of cell great numbers was performed during everyday observations. For exposition of the most thick cell regions, additional "ph3" phase-contrast filter was applied. After three weeks of culture samples were fixed in 4\% paraformaldehyde for Oil Red $\mathrm{O}$ staining and in same fixing agent for fluorescent imaging. Prior to fixation, cells were incubated with MitoRed fluorescent dye for 30 minutes (MitoRed, 100nM, Sigma). For visualization of nuclei and actin, cells were permeabilized with $0,1 \%$ triton $\mathrm{x}-100$ for 10 minutes, triple washed with PBS containing $1 \%$ of FBS and incubated for one hour with phalloidin conjugated with fluorophore (Atto-488, 1:500, Sigma). After triple washing, cells were counterstained with DAPI for 5 minutes. Finally samples were observed by means of inverted, fluorescent microscope in wavelengths $580 \mathrm{~nm}$ for mitochondria, $523 \mathrm{~nm}$ for actin and 454nm for nuclei. Pictures were taken with digital camera (Cannon PC1200), than were put together with Photoshop 7.0 (Adobe). For lipid staining, fixed cells were washed with 70\% isopropyl alcohol, incubated with dye for 20 minutes, washed again with 70\% isopropyl alcohol, counterstained with haematoxylin and washed with tap water. Samples were analyzed with inverted microscope; pictures were taken with digital camera as it was previously described.

\section{RESULTS}

Olfactory bulb. In olfactory bulb-derived cultures we noticed mostly fibroblast-like cells, with single nuclei. They were growing in colonies with high density, keeping proliferative potential. After five days of culture their morphology was typical for fibroblasts (Fig. 1A). After ten days of culture, we noticed bright spots within cells using different phase contrasts filters. Oil Red $\mathrm{O}$ staining confirmed the lipid character of these structures (Fig. 1B). After three weeks of culture, lipid droplets were more numerous. Mitochondria were distributed mainly near nuclei (Fig. 1C). The architecture of cytoskeleton was mostly uniform, with sparse presence of more extensive and bigger cells, which were often polynucleated (Fig. 1D). Rarely, we saw cells grouped in couples, which differed in size (Fig. 2A).

Cerebrum. In cultures derived from cerebrum, we noticed heterogeneity of morphotypes. Cells had irregular shape, were often connected with each other and formed random colonies. Occasionally, they exist as couples of cells dissimilar in size (2B). All cells were rich in bright lipid regions from the first days of culture (Fig. 3A, 3B). Their proliferative capacity was limited; therefore cell number was relatively constant during three weeks of culture. In case of this population, mitochondria were also localized near nuclei, next to mitochondria (Fig. 3C). Cytoskeleton architecture shows significant variability with no prevalence of any morphological type (Fig. 3D). One of observed morphotype could be qualified as epithelial-like. In this cell population, 


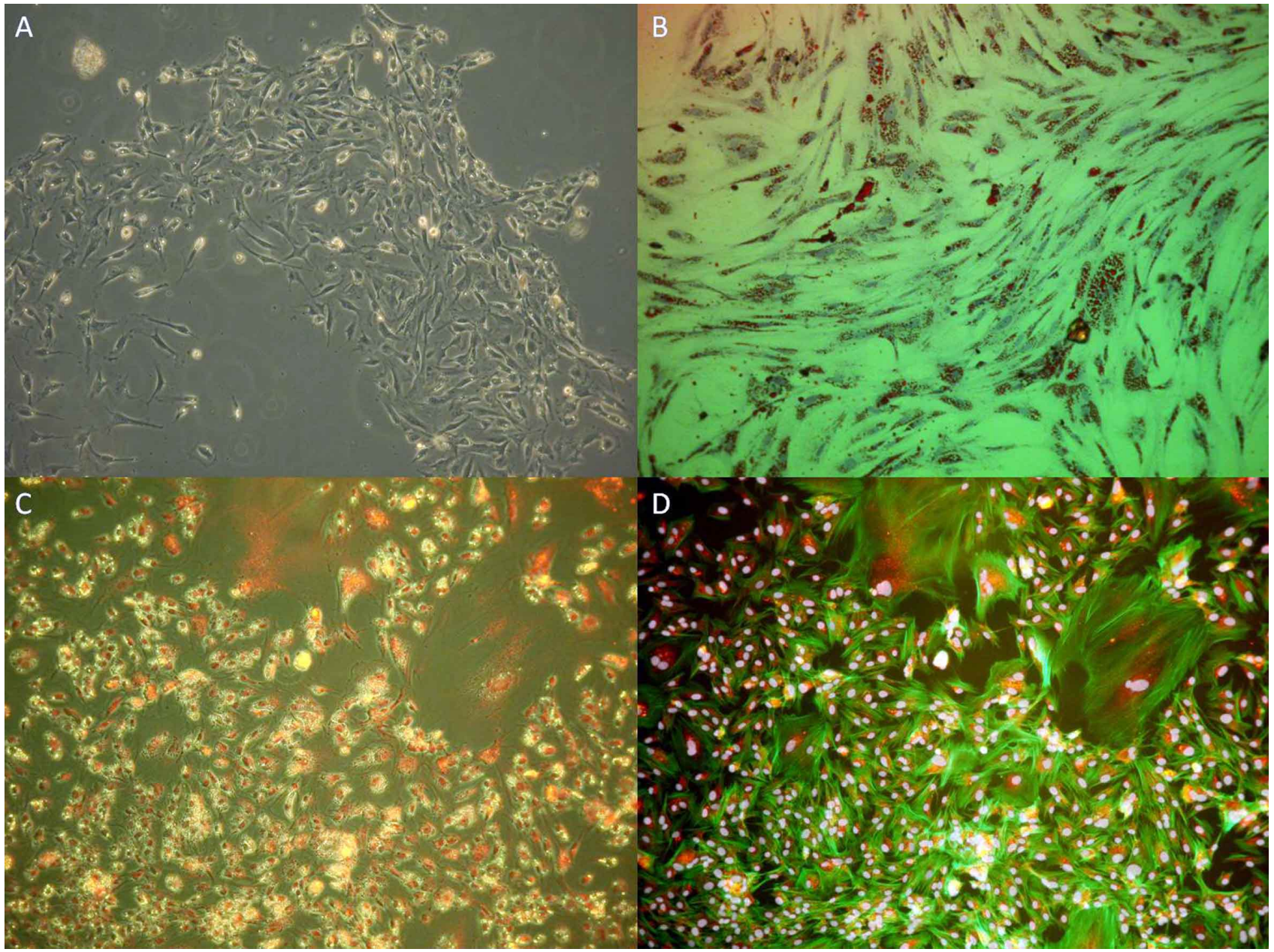

Fig. 1. Glial adherent cells, derived from olfactory bulb in culture. A. Inverted, phase-contrast microscope. B. Oil Red O staining. C. Inverted, phase-contrast microscope with fluorescence staining added - mitochondria in red. D. Fluorescent microscope, actin in green, mitochondria in red, nuclei in grey. Magnifications 100x.

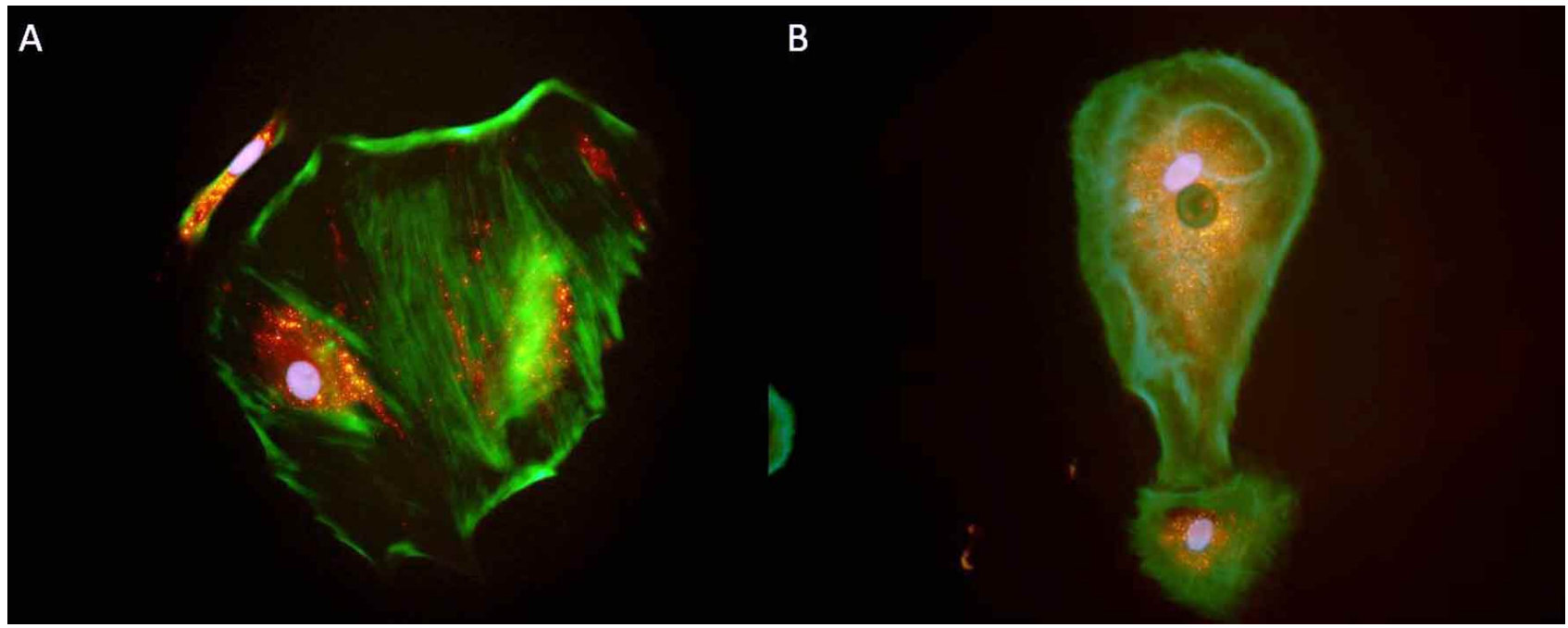

Fig. 2. Glial cell couples from olfactory bulb (A) and from cerebrum (B). Fluorescent microscope - actin in green, mitochondria in red, nuclei in grey. Magnifications 200x. 


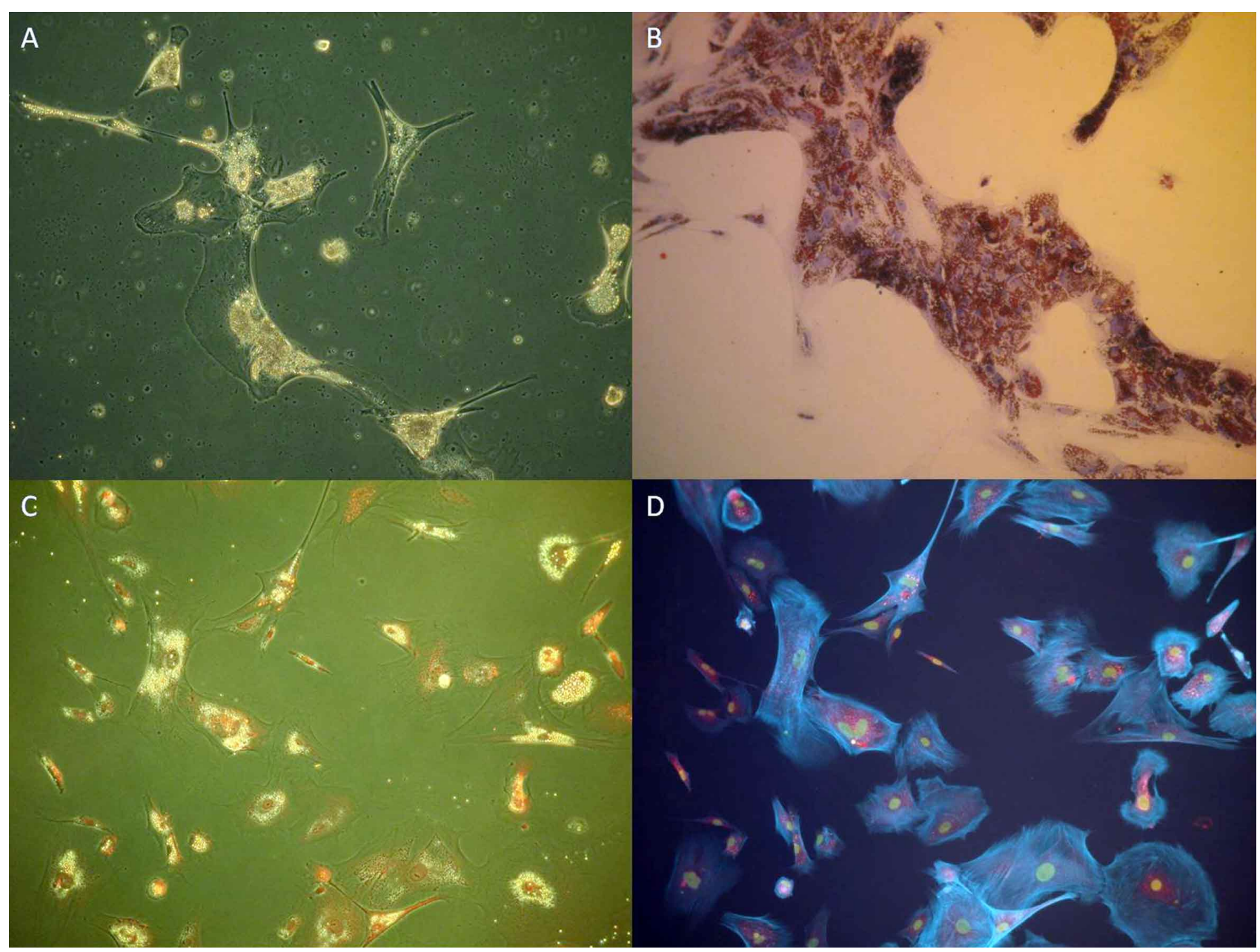

Fig. 3. Glial adherent cells, derived from olfactory bulb-depleted brain tissue after two weeks in culture. A. Inverted, phase-contrast microscope. B. Oil Red O/hematoxylin staining. C. Inverted, phase contrast microscope picture with fluorescent image added, mitochondria visible in red. D. Fluorescent combined image, actin in blue, mitochondria in red, nuclei in green. Magnifications 100x.

we also detect bright and extensive lipid spots (Fig. 4A). Cells were growing in dense colonies, had round shape kept by their actin, and contained one or more nuclei. Correlation between lipid vesicles localization and mitochondria distribution was prominent; we showed it by different microscopic techniques (Fig. 4A, 4B). This situation was seen also in olfactory bulb-derived cultures, although mitochondria were localized in filopodia as well (Fig. 4C, 4D).

\section{DISCUSSION}

Central nervous system in adult reptiles kept the growth ability. It is clearly shown just by a significant, agesize related increase in brain mass, and increase in number of cortical neurons (Kaslin et al., 2008). Therefore, this growth must be connected with proliferative activity of particular cell populations. None of observed cells were p75+/ GFAP+, so we could not differentiate cell population on astrocytes and oligodendrocytes. Probably due to differences in protein sequences and conformations in reptiles, staining antibodies were incompatible with these cells. Therefore, it could only be done on the basis of morphological analyses. In physiological condition, three types of progenitor cells were described as giving the origin to new neurons neuroepithelial, radial glial and astrocytes (Doetsch, 2003). In our experiment, we noticed only one cell type which significantly multiplied in culture -fibroblast-like, mononuclear cells. They were present mostly in olfactory bulb-derived cultures, but also were incidentally seen in cerebrum-derived ones. Their morphology was similar to mammalian mesenchymal stem cells, with fibroblastic shape and storiform growth pattern. Differences in cell number of 


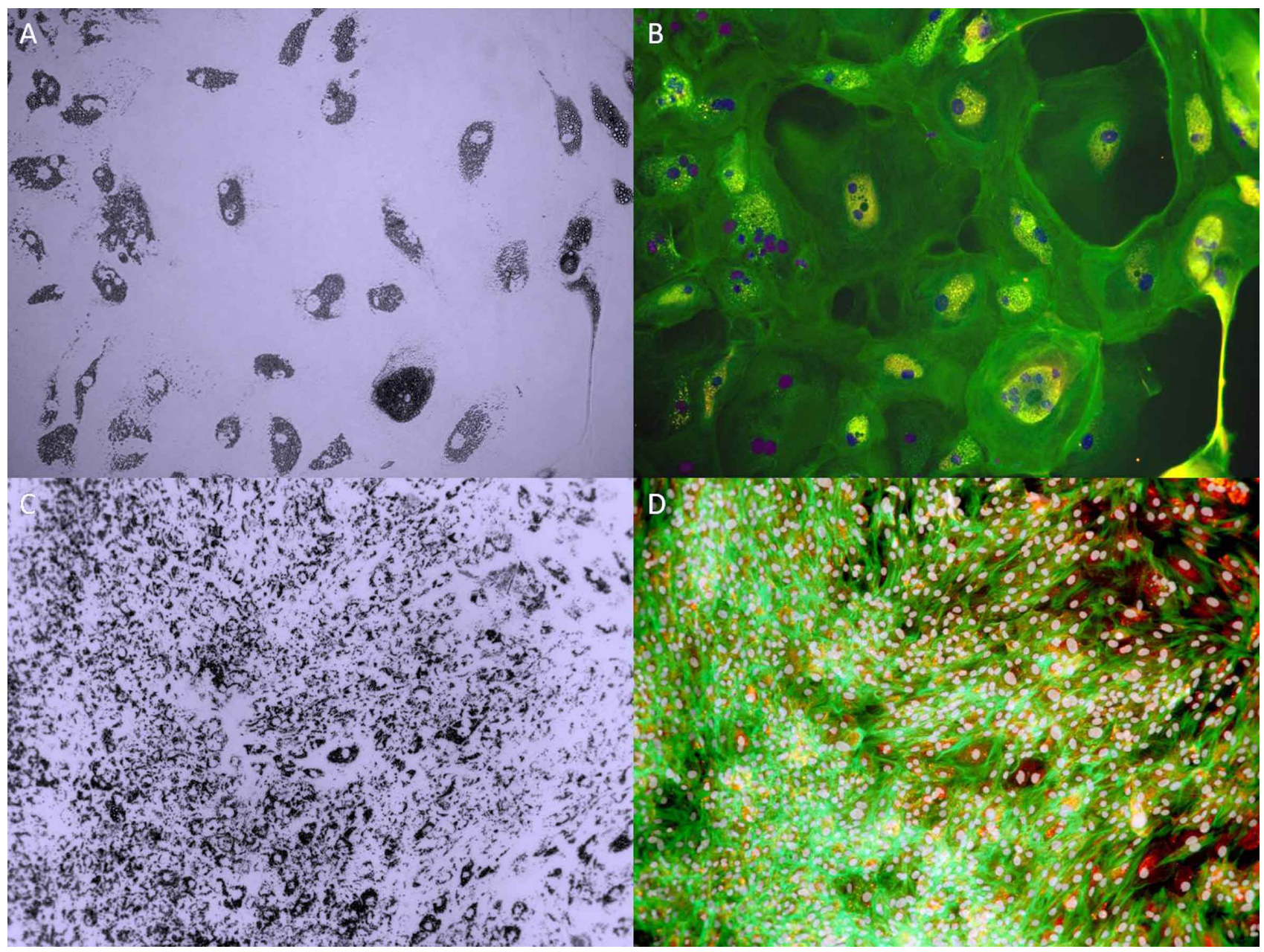

Fig. 4. Lipid droplets and mitochondria distribution in brain derived (A, B) and OB-derived (C, D) cells A. Inverted, phase-contrast microscope, magnification 200x. B. Fluorescent microscope, actin in green, mitochondria in yellow, nuclei in blue, magnification 200x. C. Inverted, phase-contrast microscope, magnification 100x. D. Fluorescent microscopy, actin in green, mitochondria in red, nuclei in grey, magnification 100x.

this morphotype within these two brain regions may be correlated with their function - smell sense is crucial for reptiles, so it remains very active. Therefore, stem cells from olfactory should be more numerous.

Emergence of lipid droplets in these cells during later stage of culture could be connected with reptile poikilothermia. When the environmental conditions are optimal, animals store the reserve material in form of lipids as well as glycogen (Seebacher \& Franklin, 2005). However, correlation between lipid vesicles and mitochondria distributions points on lipid usage for current metabolism rather than for storage (Shaw et al., 2008). The presence of lipid droplets is uncommon for mammalian glial cells, but in reptiles they are in large quantities. We presume that these deposits could contain the molecule directly involved in neuroregeneration.
Sparse, more extensive and polynucleated cells present within colonies had probably macrophage character. We state this based on their morphology; however it hasn't been directly confirmed yet. Cells seen in couples, noticed in cultures were considered as being observed after asymmetric division. Such phenomenon was already seen during reptilian neurogenesis, which was described by Doetsch. In cerebrum-derived cultures, variability in morphologies undoubtedly resulted from high specialization of cells present within this brain region. Ultimate differentiation explains the lack of proliferative activity; however epithelial-like cells which colonized area around tissue explants appear to proliferate, in limited manner. Their morphology was typical for neuroepithelium, but no evidence of neural stemness was achieved. Incidentally seen cell couples, with cells of different size were also considered as cells after asymmetric division. 
In our research, glial cells from species known from its neuroregenerative potential were successfully maintained in artificial environment. Our established cell cultures allowed us to describe morphology of cells derived from reptile CNS tissues, also points out particular population suspected for being involved in neuroneogenesis. These results will be used for future research connected with CNS regeneration process, projecting of different biomaterials or novel pharmaceutics.

GRZESIAK, J.; MARYCZ, K.; SZAREK, D. \& JARMUNDOWICZ, W. Caracterización morfológica de las células gliales del Gecko (Eublepharis macularius) en cultivo. Int. J. Morphol., 31(3):826-831, 2013.

RESUMEN: El sistema nervioso central de los reptiles tiene la capacidad de crecer y regenerarse durante la vida adulta del animal. Por lo tanto, las células de SNC creadas de esta clase de animales deberían componerse de sustancias o moléculas que permiten la neuroregeneración. Las células que participan directamente en este proceso no han sido claramente caracterizadas, especialmente en el entorno de cultivo celular. La morfología de las células adherentes gliales de reptiles deben ser reconocidas y diferenciarse respecto a las células del SNC de mamíferos. Se aislaron células gliales del bulbo olfatorio y el cerebro del Gecko (Eublepharis macularius) y se cultivaron por separado. Se observaron poblaciones de células con capacidad proliferativa en ambos tipos de cultivos. Además, se detectaron moléculas de depósitos lipídicos dentro de su citoplasma, y su localización se correlacionó con la posición de las mitocondrias. Esta información puede ser útil en la búsqueda de nuevas sustancias bioactivas que participan en la regeneración del sistema nervioso central.

PALABRAS CLAVE: Células gliales; Neurogénesis; Neuroregeneración; Reptil.

\section{REFERENCES}

Doetsch, F. The glial identity of neural stem cells. Nat. Neurosci., 6(11):1127-34, 2003.

Hannun, Y. A. \& Obeid, L. M. Principles of bioactive lipid signalling: lessons from sphingolipids. Nat. Rev. Mol. Cell Biol., 9(2):139-50, 2008.

Kaslin, J.; Ganz, J. \& Brand, M. Proliferation, neurogenesis and regeneration in the non-mammalian vertebrate brain. Philos. Trans. R. Soc. Lond. B. Biol. Sci., 363(1489):10122, 2008.

Ramón-Cueto, A. \& Muñoz-Quiles, C. Clinical application of adult olfactory bulb ensheathing glia for nervous system repair. Exp. Neurol., 229(1):181-94, 2011.

Ratajczak, M. Z.; Kim, C. H.; Abdel-Latif, A.; Schneider, G.; Kucia, M.; Morris, A. J: et al. A novel perspective on stem cell homing and mobilization: review on bioactive lipids as potent chemo attractants and cationic peptides as underappreciated modulators of responsiveness to SDF-1 gradients. Leukemia, 26(1):63$72,2012$.

Seebacher, F. \& Franklin, C. E. Physiological mechanisms of thermoregulation in reptiles: a review. J. Comp. Physiol. B, 175(8):533-41, 2005.
Shaw, C. S.; Jones, D. A. \& Wagenmakers, A. J. Network distribution of mitochondria and lipid droplets in human muscle fibres. Histochem. Cell Biol., 129(1):65-72, 2008.

Wang, Y.; Jiang, X.; Liu, Y.; Gu, X.; Huan, Y.; Ren, L.; et al. Molecular cloning and altered expression of $\mathrm{Pbx} 4$ in the spinal cord during tail regeneration of Gekko japonicus. Brain Res. Bull., 80(6):414-21, 2009.

Wang, Y.; Wang, R.; Jiang, S.; Zhou, W.; Liu, Y.; Wang, Y.; et al. Gecko CD59 is implicated in proximodistal identity during tail regeneration. PLoS One, 6(3):e17878, 2011.

\section{Correspondence to: \\ MSc Jakub Grzesiak \\ Electron Microscopy Laboratory \\ University of Environmental and Life Sciences \\ Kozuchowska 5b 51-631 Wroclaw \\ POLAND}

Tel: +48713205888

Email: grzesiak.kuba@gmail.com

Received: 18-01-2013

Accepted: 01-07-2013 